\title{
A Comparative Evaluation of Gustafson's Formula and New Formula for Age Estimation in India - A Forensic Study
}

\author{
Manas Bajpai ${ }^{1}$, Nilesh Pardhe ${ }^{1}$, Manish Kumar ${ }^{2}$, Shyam Agrawal ${ }^{3}$ \\ ${ }^{1}$ Department of Oral and Maxillofacial Pathology, NIMS Dental College, Jaipur, India; \\ ${ }^{2}$ Department of Prosthodontics Crown and Bridge, NIMS Dental College, Jaipur, \\ India; \\ ${ }^{3}$ Department of Endodontics, NIMS Dental College, Jaipur, India \\ Received April 8, 2015 ; Accepted September 16, 2015.
}

Key words: Age estimation - Physiological changes - Gustafson's formula Forensic odontology

\begin{abstract}
The choice to use teeth for age determination is well accepted due to their longevity ability of being resilient to change. The total of 228 extracted teeth collected from the patients visited to the Department of Oral and Maxillofacial Surgery, NIMS Dental College, Jaipur, the teeth were without dental fillings and without and/or cavity selected. The known age was from 21 to 70 years with the average age of 43.46 years. For age estimation the method according to Gustafson was used. Every tooth was subject to longitudinal section of the midpulpal area. The following dental parameters were studied in each case: attrition, periodontal bone loss, root translucency, secondary dentin deposition, cementum apposition and root resorption. Total scores of different parameters plotted against the chronological age and regression formula was obtained. Using this formula ages were estimated, Gustafson formula was also applied in the same scores and ages estimated. The results of the chronological and estimated age by both formulae have been statistically compared using Pearson's correlation and regression analysis. The results showed strong correlation $(0.92 ; p<0.001)$ between chronological and estimated age by using both formulae. We found the mean error of \pm 5.47 by using newly derived and formula and \pm 6.35 by Gustafson's formula. As a result of our study it was found that newly derived formula provides better results in comparison with Gustafson's formula in Indian population. A positive correlation between age and total scores of physiological changes also revealed.
\end{abstract}

Mailing Address: Dr. Manas Bajpai, Department of Oral and Maxillofacial Pathology, NIMS Dental College, Jaipur, India; e-mail: dr.manasbajpai@gmail.com 


\section{Introduction}

Age estimation is a subdiscipline of the forensic sciences and should be an important part of every identification process, especially when information relating to the deceased is unavailable (Parikh, 1990). The science dealing with establishing identity of a person by teeth is popularly known as Forensic Odontology or Forensic Dentistry (Sengupta et al., 1999). Many variables have been used as age determinants and even dental histological techniques can contribute to age estimation. The choice to use teeth for age determination is well accepted due to their longevity ability of being resilient to change (Pillay, 2004). Gustafson (1950) was first to note the morphological changes in the structure of teeth. These were attrition, periodontosis, secondary dentition, cementum apposition, root translucency and root resorption. He awarded a score of 0 to 3 based upon visual severity of changes and estimated age. He calculated age using the regression formula derived from his observation: $Y=3.52 X+8.88(X-$ total score, $Y$ - estimated age). Gustafson established that the difference between calculated age and real age would not exceed \pm 3.6 years in $33 \%$ of cases, \pm 7.3 years in $4.5 \%$ cases, \pm 9.1 years in $1 \%$ of cases and \pm 10.9 years in $0.3 \%$ cases. The present study dealt with the comparative analysis of age estimation by newly derived formula and Gustafson's formula in Indian population.

\section{Material and Methods}

Selection of the patients

Total of 228 cases visited to the Department of Oral and Maxillofacial Surgery, NIMS Dental College, Jaipur, for extraction from December 2013 to January 2015 were taken in the study for teeth collection. The known age was from 21 to 70 years with the average age of 43.46 years. The cases divided in 5 age groups $(21-30,31-40,41-50,51-60$, and $61-70)$. The most number of cases

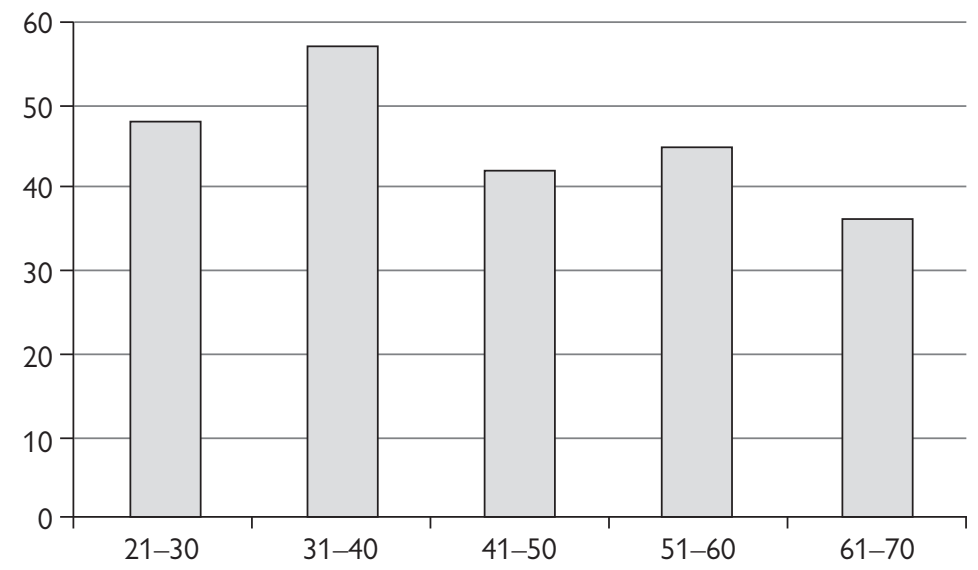

Figure 1 - Number of cases according to the age group. 
belonged to age group 31-40 with 57 cases. Least number of cases belonged to age group 61-70 with 36 patients (Figure 1). The ethical clearance and consents of the patients were taken prior to the study. The following dental parameters were studied in each case: attrition, periodontal disease, cementum apposition, secondary dentine deposition, root translucency and root resorption according to Gustafson method. After the extraction the teeth were cleaned under running water, disinfected in the $3 \% \mathrm{H}_{2} \mathrm{O}_{2}$ and dried at the room temperature. Every tooth was embedded in light cure resin. The extent of periodontal disease was recorded before the extraction of the tooth. Ground section was prepared by hand grinding which was done first with lathe and then with rough carborundum stone until a section of $1 \mathrm{~mm}$ was obtained and at this thickness, the root translucency was noted. Grinding was further done using fine stone until the section of $0.25-\mathrm{mm}$ thickness is left. Finally, cleaned and dried section was mounted on slide and viewed under microscope for secondary dentine, cementum apposition and root resorption according to the four point allotment system given by Gustafson.

\section{Exclusion criteria}

1. Third molar

2. Patient with medical and drug history

3. Trauma from occlusion

4. Abnormal oral habits

5. Congenital anomalies of teeth

6. Pathologies affecting teeth

\section{Four point allotment system as per Gustafson's method}

Attrition (A)

A0 - No attrition

A1 - Attrition limited to enamel level

A2 - Attrition limited to dentine level

A3 - Attrition up to pulp cavity

Periodontal disease $(P)$

P0 - No obvious periodontal disease

P1 - Beginning of periodontal disease but no bone loss

P2 - Periodontal disease more than $1 / 3^{\text {rd }}$ of the root

$\mathrm{P} 3$ - Periodontal disease more than $2 / 3^{\text {rd }}$ of the root

Secondary dentine (S)

SO - No secondary dentine formation

S1 - Secondary dentine up to upper part of pulp cavity

S2 - Secondary dentin up to $2 / 3^{\text {rd }}$ of the pulp cavity

S3 - Diffuse calcification of entire pulp cavity 
Root translucency $(T)$

T0 - No translucency

T1 - Beginning of translucency

T2 - Translucency more than $1 / 3^{\text {rd }}$ of the apical root

T3 - Translucency more than $2 / 3^{\text {rd }}$ of the apical root

Cementum apposition (C)

CO - Normal cementum

C1 - Thickness of cementum more normal

C2 - Abnormal thickness of cementum near the apex of the root

C3 - Generalized abnormal thickness of cementum throughout the apex of the root

\section{Statistical analysis}

The statistical analysis was performed using MedCalc Software (Version 10, Mariakerke, Belgium). The results of the chronological and estimated age by both methods were compared by using Person's correlation coefficient and regression analysis.

\section{Results}

Total of 228 cases were taken and divided into five age groups (Table 1). Six physiological factors recorded according to Gustafson's method. The total score of six factors plotted against the actual age and regression formula $Y=5.6 X+1.81$ $(X$ - total score, $Y$ - estimated age) obtained (Figure 2). Using this formula age estimated. The Gustafson's formula $(Y=4.5 X+11.43)$ also applied in the same scores and age estimated. Estimated age by Gustafson and newly derived formula in different age groups were found to be significant $(p<0.001)$ except in the age group 61-70 (Table 2). Comparing estimated age by both formulae the mean error of \pm 5.47 was found using newly derived formula and \pm 6.35 was found using Gustafson's formula. A correlation coefficient of 0.92 was found by using both formulae (Table 3). It was also revealed that scores are increased with increasing age (Figure 3).

Table 1 - Mean age and mean total score according to the case distribution in different age groups

\begin{tabular}{lcrc}
\hline Age group & Number of cases & Mean age \pm SD & Mean score \\
\hline $21-30$ & 48 & $25 \pm 2.86$ & 5.00 \\
$31-40$ & 57 & $34.8 \pm 1.73$ & 5.60 \\
$41-50$ & 42 & $46 \pm 2.69$ & 8.25 \\
$51-60$ & 45 & $54.9 \pm 2.78$ & 9.25 \\
$61-70$ & 36 & $65.5 \pm 2.50$ & 11.30 \\
\hline
\end{tabular}

SD - standard deviation 


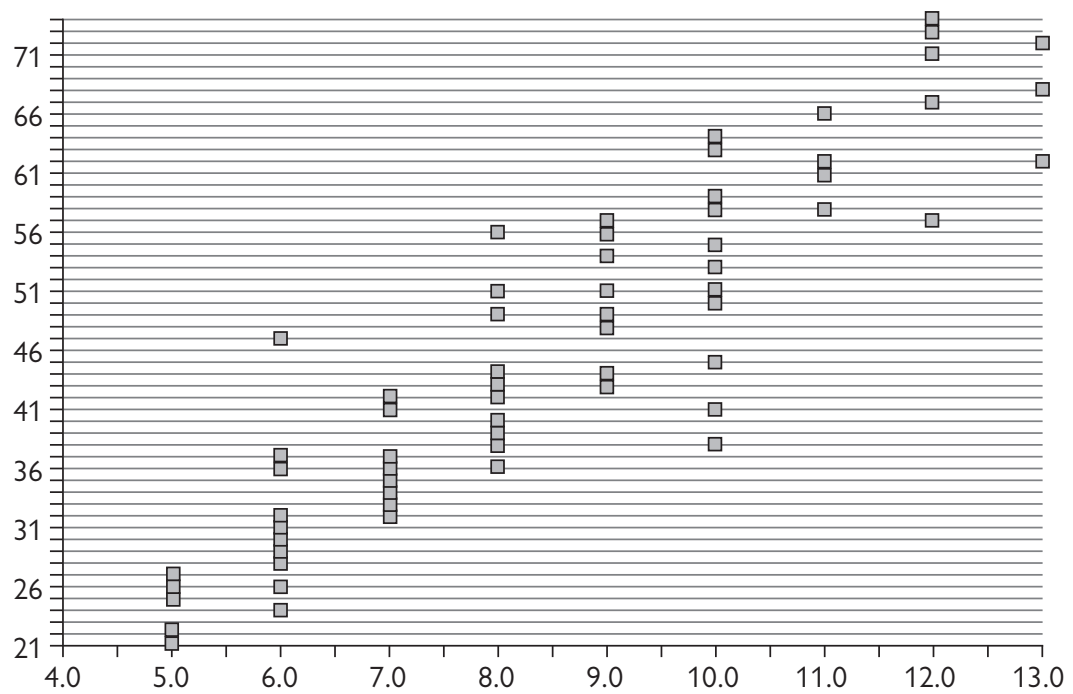

Figure 2 - Plots of regression analysis between scores and actual age (X-axis - total score, Y-axis - actual age).

Table 2 - Accuracy of age estimation by newly derived formula and Gustafson formula in different age groups

\begin{tabular}{lcccc}
\hline \multirow{2}{*}{$\begin{array}{l}\text { Age group } \\
\text { (years) }\end{array}$} & \multicolumn{2}{c}{ Mean age \pm SD } & \multirow{2}{*}{ P-value } & Significance \\
\cline { 2 - 3 } & $\begin{array}{l}\text { Estimated age } \\
\text { (new formula) }\end{array}$ & $\begin{array}{c}\text { Estimated age } \\
\text { (Gustafson formula) }\end{array}$ & & \\
\hline $21-30$ & $29.81 \pm 4.79$ & $33.09 \pm 4.02$ & $<0.001$ & $\mathrm{~S}$ \\
$31-40$ & $40.38 \pm 3.36$ & $42.43 \pm 2.70$ & $<0.001$ & $\mathrm{~S}$ \\
$41-50$ & $48 \pm 5.79$ & $48.55 \pm 4.65$ & $<0.001$ & $\mathrm{~S}$ \\
$51-60$ & $53.26 \pm 2.11$ & $53.05 \pm 2.25$ & $<0.001$ & $\mathrm{~S}$ \\
$61-70$ & $65.27 \pm 4.57$ & $62.43 \pm 3.67$ & $>0.050$ & NS \\
\hline
\end{tabular}

Table 3 - Mean error, correlation coefficient and significance found in age estimation by newly derived formula and Gustafson's formula

\begin{tabular}{lcccc}
\hline Formula & Number of cases & ME & $r$ & P-value \\
\hline Newly derived & 228 & \pm 5.47 & 0.92 & $<0.001$ \\
Gustafson & 228 & \pm 6.35 & 0.92 & $<0.001$ \\
\hline
\end{tabular}

ME - mean error; $r$ - correlation coefficient

\section{Discussion}

The concept of the age and time had come into the mind of the human being for centuries, possibly millennia. Age estimation can prove critical part in victim identification process. In cases of unknown dead bodies age estimation becomes 


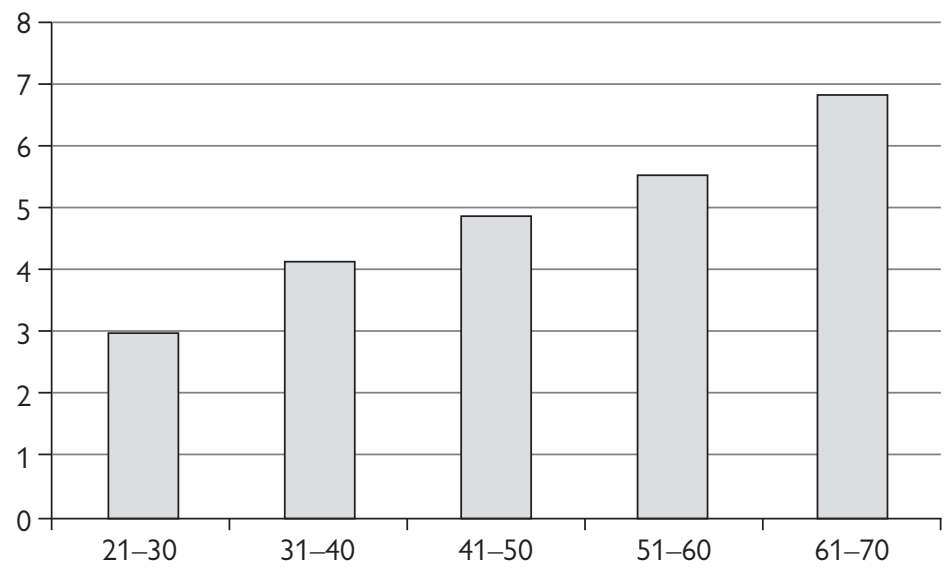

Figure 3 - Scores increasing with age.

necessary if there is no ante mortem information available and a personal profile has to be reconstructed. In addition, age estimation can be done in precious archaeological skeletal material dating back to hundreds of years. Physiological changes of teeth to estimate the age was first utilized by Gustafson in 1950; later this method was modified by number of researchers for the improvement of accuracy. In present study six physiological changes were studied and age was estimated with the mean error of \pm 5.47 in contrary to Gustafson's \pm 3.63 . Age also estimated using Gustafson's formula and the mean error was found to be \pm 6.35 . The mean error found in the present study was greater than Singh et al. (2004) \pm 2.16 years, Bajpai (2011) \pm 4.86 years, Shrigiriwar and Jadhav (2013) \pm 4.43 years, Bajpai et al. (2012) \pm 4.52 years and John et al. (2014) \pm 4.00 years, but it was lesser than Maples and Rice (1979) \pm 7.03 years and Chandler (2013) \pm 11.6 to \pm 13.7 years.

\section{Conclusion}

Different studies have shown different results. The error can be multifactorial including different oral habits and oral hygiene of different population samples and limited sample size. The present study revealed that age estimation by Gustafson's formula shows a greater difference with actual age in comparison with newly derived formula which depicts the viability of age estimation by Gustafson's formula in Indian population is not relevant.

\section{References}

Bajpai, M. (2011) Age estimation using physiological changes of teeth. Eur. J. Exp. Biol. 1(4), 104-108.

Bajpai, M., Mishra, N., Sharma, P. (2012) A comparison of the accuracy of Maples and Rice and newly derived formula for age estimation: a forensic study. J. Orofac. Res. 2(1), 1-4. 
Chandler, S. (2013) A study to determine the accuracy of Gustafson's method of age estimation on adult teeth when applied to a sample population of Western Cape. Available at: www.hdl.handle.net /11394/3264.

Gustafson, G. (1950) Age determination from teeth. J. Am. Dent. Assoc. 41, 45-54.

John, K. M., Joseph, V. J., Arul, D. P., Sandeep, L., Anulekh, B., Anupama (2014) Accuracy of age estimation in Kerala population using Gustafson's formula: a forensic evaluation. IOSR J. Dent. Med. Sci. 13(2), 39-44. Maples, W. R., Rice, P. M. (1979) Some difficulties in the Gustafson's dental age estimations. J. Forensic Sci. 24(1), 168-172.

Parikh, C. K. (1990) Parikh's Textbook of Medical Jurisprudence and Toxicology, $5^{\text {th }}$ Edition. CBS Publishers and Distribution, Bombay.

Pillay, V.V. (2004) Textbook of Forensic Medicine and Toxicology, $14^{\text {th }}$ Edition. Paras Medical Publishers, Bangalore. Sengupta, A., Whittaker, D. K., Shellis, R. P. (1999) Difficulties in estimating age using root dentine translucency in human teeth of varying antiquity. Arch. Oral Biol. 44(1), 889-899.

Shrigiriwar, M., Jadhav, V. (2013) Age estimation from physiological changes of teeth by Gustafson's method. Med. Sci. Law. 53(2), 67-71.

Singh, A., Gorea, R. K., Urveshi, S. (2004) Age estimation from the physiological changes of teeth. J. Indian Acad. Forensic Med. 26(3), 94-96. 